\title{
A CLINICOPATHOLOGICAL STUDY TO ESTABLISH THE CORRECTNESS OF THE DIAGNOSIS OF ACUTE APPENDICITIS IN CASES OF ACUTE RIGHT LOWER QUADRANT PAIN OF ABDOMEN
}

\author{
Debasish Patnaik1, Amulya Mohan Acharya2, Sai Bharath Sunkara³, Treena Minz"4, Saikh Kasif Sahajada ${ }^{5}$ \\ ${ }_{1}^{1}$ Associate Professor, Department of Surgery, Hitech Medical College \& Hospital, Bhubaneswar, Odisha, India. \\ ${ }^{2}$ Assistant Professor, Department of Surgery, Hitech Medical College \& Hospital, Bhubaneswar, Odisha, India. \\ 33rd Year Postgraduate Trainee, Department of Surgery, Hitech Medical College \& Hospital, Bhubaneswar, Odisha, India. \\ ${ }_{4}^{4}$ nd Year Postgraduate Trainee, Department of Surgery, Hitech Medical College \& Hospital, Bhubaneswar, Odisha, India. \\ ${ }^{51}{ }^{\text {st }}$ Year Postgraduate Trainee, Department of Surgery, Hitech Medical College \& Hospital, Bhubaneswar, Odisha, India.
}

\section{ABSTRACT}

\section{BACKGROUND}

Acute appendicitis is a common surgical condition that requires prompt diagnosis in order to minimize morbidity and avoid serious complications. Accurate identification of patients who require immediate surgery as opposed to those who will get benefit from active observation is not always easy. ${ }^{1}$ Therefore, several scoring systems have been devised to aid decision making in doubtful cases, including Ohmann, Alvarado, Eskelinen and several others. These scores utilize routine clinical and laboratory assessment, thus being simple to use in a variety of clinical settings. We wanted to study the various clinical presentations of patients with suspected acute appendicitis, evaluate diagnostic accuracy of modified Alvarado score and Ohmann score in corelation to histopathology report for diagnosis of acute appendicitis. To determine the sensitivity, specificity, positive predictive value, negative predictive value and diagnostic accuracy of the individual scoring systems and ultrasonography and the same parameters when they are combined together.

\section{METHODS}

The present descriptive study was undertaken at Hi Tech Medical College, Bhubaneswar, Odisha. During the period of October 2016 to November 2018. After thorough clinical examination and routine blood investigation, every patient was allotted modified Alvarado score and Ohmann score. Ultrasonography, intraoperative findings, histopathological examination were done. Sample size was taken for convenience.

\section{RESULTS}

US had a sensitivity of $90.32 \%$, specificity $80.95 \%$, PPV 87.5\%, NPV 85\% and diagnostic accuracy of $86.54 \%$. Alvarado score gives sensitivity $90.32 \%$, specificity $61.90 \%$, PPV 77.78\%, NPV $81.25 \%$ and diagnostic accuracy of $78.85 \%$. Ohmann score yields sensitivity $80.65 \%$, specificity $80.95 \%$, PPV $86.21 \%$, NPV 73.91\% and diagnostic accuracy of 80.77\%. When modified Alvarado score combined with ultrasonographic finding then sensitivity, specificity, PPV, NPV and diagnostic accuracy increases to $96.3 \%$, 100\%, 100\%, 90\% and 97.22\% respectively. When Ohmann score also combined with ultrasonographic findings sensitivity, specificity, PPV, NPV and diagnostic accuracy increases to $92.31 \%, 88.24 \%, 92.31 \%, 88.24 \%$ and $90.69 \%$ respectively.

\section{CONCLUSIONS}

When any of the two scoring systems i.e. modified Alvarado score and Ohmann score was used along with US, it increased the sensitivity, specificity, PPV, NPV, diagnostic accuracy and reduced the negative appendectomy rates. So, combination of scoring system with ultrasonography is very helpful to correctly diagnose acute appendicitis.

\section{KEY WORDS}

Right Iliac Fossa Pain, Ohmann Alvarado Score, Ultrasonography Sensitivity

HOW TO CITE THIS ARTICLE: Patnaik D, Acharya AM, Sunkara SB, et al. A clinicopathological study to establish the correctness of the diagnosis of acute appendicitis in cases of acute right lower quadrant pain of abdomen. J. Evolution Med. Dent. Sci. 2019;8(27): 2171-2175, DOI: $10.14260 /$ jemds/2019/476

\section{BACKGROUND}

Acute appendicitis is a common surgical condition that requires prompt diagnosis in order to minimize morbidity and avoid serious complications. Accurate identification of patients who require immediate surgery as opposed to those who will get benefit from active observation is not always easy. ${ }^{1}$ Therefore, several scoring systems have been devised to aid decision making in doubtful cases, including Ohmann,

'Financial or Other Competing Interest': None.

Submission 25-06-2019, Peer Review 06-06-2019,

Acceptance 14-06-2019, Published 08-07-2019.

Corresponding Author:

Dr. Amulya Mohan Acharya,

Department of Surgery,

Hitech Medical College \& Hospital,

Bhubaneswar-751025, Odisha, India.

E-mail: dramulya.acharya@gmail.com

DOI: $10.14260 /$ jemds $/ 2019 / 476$
Alvarado, Eskelinen and several others. These scores utilize routine clinical and laboratory assessment, thus being simple to use in a variety of clinical settings. Although ancient texts have scattered description of surgery being undertaken for ailments sounding like appendicitis, credit for performing the first appendectomy goes to Claudius Amy and a surgeon at St. George's Hospital in London, in 1936.2 In 1824, Louyer Villermay presented a paper before the Royal Academy of Medicine in Paris. In 1827, Francois Melier, a French Physician, reported six autopsy cases and was the first to suggest the antemortem recognition of appendicitis. Baron Guillaume Dupuytren believed that inflammation of cecum was the main cause of pathology or the right lower quadrant pain. The term typhlitis was used to describe right lower quadrant inflammation. In 1839, Bright and Addison described the symptoms of appendicitis and identified the primary cause of inflammatory processes of the right lower quadrant. Reginald Fitz, a Professor of Pathologic anatomy at 
Harvard, is credited with coining the term appendicitis. Initial surgical therapy for appendicitis was primarily designed to drain right lower quadrant abscesses that occurred secondary to appendiceal perforation. First surgical treatment for appendicitis or perityphlitis without abscess was carried out by Hancock in 1848. The first published account of appendectomy for appendicitis was by Kronlein in 1886. The greatest contributor to the advancement in the treatment of appendicitis was Charles McBurney. In 1889, he published a paper in the New York state Medical Journal describing the indications of appendicectomy. He described the McBurney's point in this paper. In 1894 McBurney published a paper describing the incision that bears his name. Laparoscopic appendectomy was first reported by the gynaecologist Kurt Semm in 1982 but has only gained widespread acceptance in recent years. The surgical treatment of appendicitis is one of the great public health advances of the last 150 years. Appendectomy for appendicitis is the most commonly performed emergency operation in the world. Appendicitis is a disease of young, with $40 \%$ of cases occurring in patients between the ages of 10 and 29 years. In 1886, Fitz reported the associated mortality rate of appendicitis to be at least $67 \%$ without surgical therapy. Currently the mortality rate for acute appendicitis with treatment is reported to be $<1 \%$.

\section{Aims and Objectives}

1. To study the various clinical presentation of patients with suspected acute appendicitis.

2. To evaluate diagnostic accuracy of modified Alvarado score and Ohmann score in co-relation to histopathology report for diagnosis of acute appendicitis.

3. To determine whether diagnosis by graded compression ultrasonography improves clinical outcomes for patients with suspected appendicitis from operative point of view.

4. To determine the sensitivity, specificity, positive predictive value, negative predictive value and diagnostic accuracy of the individual scoring systems and ultrasonography and the same parameters when they are combined together.

5. To find out the incidence of the non-inflamed appendices obtained from the histopathological survey of the specimen removed. An information about the incidence of unjustified exploration can thus be obtained.

\section{METHODS}

The present descriptive study was undertaken at Hi tech medical college, Bhubaneswar, Odisha. During the period of October 2016-November 2018. 52 cases of clinically suspected acute appendicitis were selected for this prospective study. Patients were selected from all age groups and both sexes of different religion and socio-economic background. Sample size taken for convenience.

- Detailed history was elicited with due consideration to age, sex, occupation, socio-economic status and the presenting symptoms, specially the history of migratory pain to right lower quadrant, anorexia, nausea and vomiting or urinary symptoms.
- Depending on clinical details and routine blood investigation, every patient was allotted modified Alvarado score and Ohmann score.

- Ultrasonography of all patient.

- Intraoperative findings which include Position, width, length, gross appearance including the presence of inflammation, obstruction, gangrene and perforation and presence of appendicolith.

- Histopathological examination of all resected specimen were done.

Statistical testing was conducted with the statistical package for the social science system (SPSS) version 20. The sensitivity was calculated and analysed comparatively with a chi-squared test and using histopathology as gold standard.

\section{RESULTS}

The total number of cases in this study were 52 . Out of 52 patients $28(53.85 \%)$ were males and 24 (46.15\%) were females. Age distribution is shown in table I.

\begin{tabular}{|c|c|c|c|c|}
\hline \multirow{2}{*}{ Age (in Yrs.) } & \multirow{2}{*}{ No. of Patients } & \multirow{2}{*}{$\%$} & \multicolumn{2}{|c|}{ Sex } \\
\cline { 3 - 5 } & & & Male & Female \\
\hline $14-25$ & 19 & 36.54 & 12 & 7 \\
\hline $26-35$ & 18 & 34.62 & 9 & 9 \\
\hline $36-45$ & 12 & 23.08 & 6 & 6 \\
\hline $46-55$ & 2 & 3.85 & 1 & 1 \\
\hline $56-65$ & 1 & 1.92 & 0 & 1 \\
\hline Total & 52 & 100 & 28 & 24 \\
\hline \multicolumn{5}{|c|}{ Table 1. Age and Sex Distribution } \\
\hline
\end{tabular}

\begin{tabular}{|c|c|c|c|}
\hline Score & No. of Patients & Percentage (\%) & Histopathology \\
\hline 1 & - & - & - \\
\hline 2 & - & - & - \\
\hline 3 & 2 & 3.85 & All-ve \\
\hline 4 & 2 & 3.85 & All-ve \\
\hline 5 & 5 & 9.62 & All-ve \\
\hline 6 & 7 & 13.46 & $3+v e, 4$-ve \\
\hline 7 & 13 & 25 & 5 -ve, 8 -t-ve \\
\hline 8 & 12 & 23.08 & 3 -ve, 9+ve \\
\hline 9 & 11 & 21.15 & $11+\mathrm{ve}$ \\
\hline \multicolumn{4}{|c|}{$\begin{array}{l}\text { Table 2. Frequency Distribution of Patients According to Alvarado } \\
\text { Scoring System }\end{array}$} \\
\hline
\end{tabular}

\begin{tabular}{|c|c|c|c|}
\hline Score & No. of Patients & $\mathbf{( \% )}$ & Histopathology \\
\hline$<6$ & 3 & 5.77 & $0+v e$ 3-ve \\
\hline $6.5-8.0$ & 4 & 7.69 & $0+v e$-ve \\
\hline $8.5-10.0$ & 8 & 15.38 & $2+$ ve 6-ve \\
\hline $10.5-11.5$ & 8 & 15.38 & $4+\mathrm{ve} 4-\mathrm{ve}$ \\
\hline $12.0-14.0$ & 18 & 34.62 & $15+\mathrm{ve} 3-\mathrm{ve}$ \\
\hline $14.5-16.0$ & 11 & 21.15 & $10+\mathrm{ve} 1$-ve \\
\hline
\end{tabular}

Table 3. Frequency Distribution of Patients According to Ohmann Scoring System

All the patients underwent ultrasonography among which 32 (61.54\%) were positive and $20(38.46 \%)$ were negative

\begin{tabular}{|c|c|c|c|c|}
\hline Scoring System & TP & TN & FP & FM \\
\hline Modified Alvarado Score & 28 & 13 & 8 & 3 \\
\hline Ohmann Score & 25 & 17 & 4 & 6 \\
\hline Ultrasonography & 29 & 17 & 4 & 3 \\
\hline \multicolumn{6}{|c|}{ Table 4. Scoring System Values } \\
\hline
\end{tabular}




\begin{tabular}{|c|c|c|c|}
\hline Values & $\begin{array}{c}\text { Modified } \\
\text { Alvarado } \\
\text { Score (\%) }\end{array}$ & $\begin{array}{c}\text { Ultrasonography } \\
\text { (\%) }\end{array}$ & $\begin{array}{c}\text { Modified Alvarado } \\
\text { Score + } \\
\text { Ultrasonography }\end{array}$ \\
\hline Sensitivity & 90.32 & 90.32 & 96.3 \\
\hline Specificity & 61.90 & 80.95 & 100 \\
\hline PPV & 77.78 & 87.5 & 100 \\
\hline NPV & 81.25 & 85 & 90 \\
\hline $\begin{array}{c}\text { Diagnostic } \\
\text { Accuracy }\end{array}$ & 78.85 & 86.54 & 97.22 \\
\hline \multicolumn{3}{|c|}{ Table 5. Comparison of Modified Alvarado Score and Ultrasonography } \\
in the Diagnosis of Acute Appendicitis \\
\hline
\end{tabular}

\begin{tabular}{|c|c|c|c|}
\hline Values & $\begin{array}{c}\text { Ohmann } \\
\text { (\%) }\end{array}$ & $\begin{array}{c}\text { Ultrasonography } \\
\text { (\%) }\end{array}$ & $\begin{array}{c}\text { Ohmann Score + } \\
\text { Ultrasonography }\end{array}$ \\
\hline Sensitivity & 80.65 & 90.32 & 92.31 \\
\hline Specificity & 80.95 & 80.95 & 88.24 \\
\hline PPV & 86.21 & 87.5 & 92.31 \\
\hline NPV & 73.91 & 85 & 88.24 \\
\hline $\begin{array}{c}\text { Diagnostic } \\
\text { Accuracy }\end{array}$ & 80.77 & 86.54 & 90.69 \\
\hline \multicolumn{3}{|c|}{ Table 6. Comparison of Ohmann Score and Ultrasonography in the } \\
Diagnosis of Acute Appendicitis \\
\hline
\end{tabular}

Out of all the patient who underwent appendicectomy, 31 (59.62\%) were histologically positive for acute appendicitis and 21 (40.38\%) were histologically negative.

All the patients were assigned modified Alvarado score, among which $36(69.23 \%)$ were positive $(\geq 7)$ and 16 $(32.69 \%)$ were negative $(\leq 6)$

\section{DISCUSSION}

Acute appendicitis remains the most common surgical emergency with a life time occurrence of $7 \% .^{3}$ But the diagnosis of acute appendicitis still represents one of the most difficult problem in surgery. It has been for long time a general surgical view that the removal of normal appendix is safer in questionable cases ${ }^{4}$, and that delay in surgery for the purpose of increasing the diagnostic accuracy in patients with acute pain leads to increased rate of perforation. ${ }^{5}$ However, such practice result in high rate of the removal of normal appendices that ranges between $15-30 \%{ }^{6}$. On the other hand, extensive observation that result in perforated appendix may lead to a poor outcome which was avoidable.

According to previous publications, the criteria for diagnostic quality have been postulated as $15 \%$ rate of negative appendectomies, $10 \%$ rate of negative laparotomies, $35 \%$ rate of potential perforations, $15 \%$ rate of over looked perforations and 5\% rate of over looked acute appendicitis. ${ }^{7,8}$ There have been many attempts to increase the accuracy of the diagnosis of acute appendicitis. Besides clinical evaluation with a variety of clinical signs and symptoms, many of the modern diagnostic tools, such as graded compression sonography, CT have proved to be effective in the diagnosis of acute appendicitis. But unfortunately, still now USG and CT often unavailable round the clock in some emergency department. So, several scoring systems have been devised for the purpose of increasing both sensitivity and specificity of the diagnosis of acute appendicitis. Scoring systems represent inexpensive noninvasive and easy to use as diagnostic aid.9,10

This study was undertaken to evaluate the accuracy of several scoring systems \& ultrasonography in the diagnosis of patients with suspected acute appendicitis.

The age of patients ranged from 14 to 65 years. The mean age was 29.94 years. This compares favourably with the reports of Abu Yousef et al (1987) (mean 26 years), Jeffrey et al (1987) (mean 25 years) and Gaensler et al (1989) (mean
26 years). In present study, the highest incidence of $36.54 \%$ was found between 14 to 25 years followed by $34.62 \%$ between 26 to 35 years. Majority of patients (69.23\%) belonged to middle class.

\section{Symptomatology}

The presenting symptoms was pain in the right lower quadrant of abdomen in all 52 cases. Shifting of pain to RIF was seen in 42 cases $(80.77 \%)$. The incidence of other common symptoms are anorexia 44 cases (84.62\%) nausea and vomiting 27 cases (55.77\%).

\section{Signs}

Tenderness in right lower quadrant was found in the 49 cases (94.23\%). Berry and Malt (1984) found in 95.9\% of appendicitis cases. Rebound tenderness was seen in 40 cases (76.92\%). Bower (1939) reported 87.5\% and Berry and Malt (1984) reported 69.5\%. Pyrexia was found in 37 cases $\mathbf{7 1 . 1 5}$ $\%)$. Total leucocyte count was found to be more than $10 \mathrm{x}$ $10^{9} / \mathrm{L}$ in 38 cases $(73.08 \%)$.

\section{Alvarado Score}

In 1986, Alvarado followed up patients admitted to surgical unit at the Nazareth Hospital in Philadelphia with suspected acute appendicitis, until surgery confirmed or refuted diagnosis. He found out eight criteria had high diagnostic accuracy for acute appendicitis. In a USG in diagnosis of acute appendicitis; in cooperating Alvarado score, it is much safer, faster and more accurate than graded compression sonography alone. Alvarado scoring system was modified by Kalen et al and named it as modified Alvarado scoring system. ${ }^{11}$

In present study, majority $69.23 \%$ had a score $>6$ and $7.7 \%$ had a score $\leq 4$. In the series of Wade et al (1994) $76 \%$ had score over 6 . Among 36 cases of positive Alvarado score ( $\geq 7$ ), 28 were histopathologically positive and only 8 were negative. But, among 16 cases of negative Alvarado score (<7) 13 cases were histologically negative and only 3 cases were histologically positive. When the results of the present study are compared with other studies, $12,13,14$ we observed that specificity, positive predictive value and negative appendectomy rate are comparable with that of the standard studies about modified Alvarado score for diagnosis of acute appendicitis The sensitivity of the present study is comparable to other studies ${ }^{12,15}$ which are prospective studies. Whereas when compared to some studies, 13,14 our study has shown higher sensitivity as these studies were retrospective studies.

The present study has shown better sensitivity, as it is a prospective study and short comings of retrospective studies are ruled out. Modified Alvarado scoring system is a dynamic one, allowing observation and critical evaluation of the clinical picture.

\section{The Ohmann Score}

Ohmann et al performed a multivariate analysis, and of initial 15 parameters, 8 were included into regression model, resulting in different values being attributed to each parameter. Originally it has been proposed that patients with scores less than 6 should not be considered to have appendicitis. Patients with scores 6 or more should undergo 
observation and those with score 12 or more should proceed to immediate appendectomy. ${ }^{10}$

In present study 29 cases (55.77\%) were positive Ohmann score $(\geq 12)$ and 23 cases $(44.23 \%)$ were negative (Ohmann score $\leq 11$ ). Majority i.e. 18 cases (34.62\%) had Ohmann score of 12 to 14 : Only 3 cases (5.77\%) had score < 6. Among 29 cases (positive Ohmann score) histopathologically positive was 25 and only 4 cases was histopathologically negative. But among 23 cases (negative Ohmann score) only 6 cases were histopathologically positive and 17 cases were histopathologically negative. In our study, Ohmann score had a sensitivity, specificity and diagnostic accuracy of $80.65 \%, 80,95 \%$ and $80.77 \%$ respectively.

\section{Ultrasonography}

All the 52 patients in this study had graded compression ultrasonographic evaluation using linear array transducers according to the situation.

The normal appendix is compressible with wall thickness of less than or equal to $3 \mathrm{~mm}$. The sonographic hallmark of appendicitis is direct visualization of the inflamed appendix. The typical appearance is that of concentrically layered, almost incompressible, sausage like structure demonstrated at the site of maximum tenderness. 16

The usual findings are-

- Visualization of non-compressible appendix as a blind ending tubular aperistaltic structure.

- Target appearance of $\geq 6 \mathrm{~mm}$ in total diameter on cross section/maximal mural wall thickness $\geq 2 \mathrm{~mm}$.

- Diffuse hypoechogenecity (associated with higher incidence of perforation).

- Lumen may be distended with anechoic/hyperechoic material

- Loss of wall layers

- Visualization of appendicolith

- Localized peri appendiceal fluid collection.

- Prominent hyperechoic mesoappendix - peri caecal fat.

If the inflamed appendix becomes non-tender on pressure, one should consider a diagnosis of spontaneous resolving appendicitis. Many clinical 'look-alikes' of appendicitis can be demonstrated reliably by ultrasound. The most common frequently encountered is the newly described bacterial ileocaecitis caused by Yersinia, Campylobacter or salmonella. Second in frequency are gynaecological conditions such as ovarian cysts, ectopic pregnancy, adnexal torsion and tubo ovarian abscess. Other ultrasonically detectable alternative conditions are caecal and sigmoid diverticulitis, cholecystitis, perforated peptic ulcer, Crohn's disease, urological conditions, small bowel obstruction and caecal carcinoma. ${ }^{17}$

Prospective studies have shown that over all accuracy of US in diagnosing acute appendicitis ranges between 87-96\% (sensitivity $75-90 \%$, specificity $86-100 \%$ ) with positive and negative predictive value of $91-94 \%$ and $89-97 \%$ respectively.17,18,19 Out of the total 52 patients in present study, appendicitis was diagnosed sonographically in 32 patients (61.54\%). Among them appendicitis confirmed in 28 patients $(87.5 \%)$ on histopathological examination (87.5\%) and only 4 cases $(12.5 \%)$ were histopathologically negative. But among the 20 sonographically negative cases, 17 patients
(85\%) were histologically negative and only 3 patients (15\%) were histologically positive. The sensitivity, specificity and diagnostic accuracy of our study was comparable with other studies. ${ }^{20}$ The visualization rate was found to be higher in males $(65.62 \%)$ than in females $(34.38 \%)$.

When modified Alvarado score and ultrasonography were compared in terms of sensitivity, specificity, positive predictive value, diagnostic accuracy and false negative cases, the results are almost same. Neither one is significantly advantageous. But in cases were modified Alvarado score is negative or equivocal, the addition of ultrasonography reduces false negative cases. In our study both the specificity and positive predictive value were $100 \%$ when both Alvarado scoring system and ultrasonography was used together. This Proves Ultrasonography has an Adjunct value in Suspected Cases of Acute Appendicitis. Similarly, it was seen that when ultrasonography was used along with Ohmann score, the sensitivity, specificity, positive predictive value, negative predictive value and diagnostic accuracy were all increased.

\section{Summary}

- Majority of the patients (71.16\%) were between 14 to 35 years.

- Males outnumbered females with $53.85 \%$ and $46.15 \%$ respectively after using scoring system and USG as diagnostic tool.

- $\quad$ Pain in the RLQ was present in all the patient. Shifting of pain to RIF was found in 42 cases (80.77\%). The other common symptoms were anorexia 44 cases $(84.62 \%)$, nausea/ vomiting 27 cases (55.77\%). Fever was present in 37 cases $(71.15 \%)$.

- Tenderness in RIF was elicited in 49 cases (94.23\%). The other common physical signs in appendicitis patients were rebound tenderness found hi RIF 40 cases (76.92\%)

- Leucocytosis above $10 \times 10^{9} / \mathrm{L}$ was present in 38 cases (73.08\%).

- Majority of patient had Alvarado score of $\geq 7$ (69.23\%)

- Majority of patient had Ohmann score of $\geq 12$ (55.77\%)

- Appendicitis was diagnosed ultrasonographically in 32 cases $(61.54 \%)$, among them histologically confirmed cases were $28(87.5 \%)$

- US give sensitivity of $90.32 \%$, specificity $80.95 \%$, PPV $87.5 \%$, NPV 85\% and Diagnostic accuracy of $86.54 \%$.

- Alvarado score gives sensitivity $90.32 \%$, specificity 61.90\%, PPV $77.78 \%$, NPV $81.25 \%$ and diagnostic accuracy of $78.85 \%$.

- Ohmann score yields sensitivity $80.65 \%$, specificity 80.95\%, PPV 86.21\%, NPV $73.91 \%$ and diagnostic accuracy of $80.77 \%$

- When modified Alvarado score combined with ultrasonographic finding then sensitivity, specificity, PPV, NPV and diagnostic accuracy increases to $96.3 \%$, $100 \%, 100 \%, 90 \%$ and $97.22 \%$ respectively.

- When Ohmann score also combined with ultrasonographic findings sensitivity, specificity, PPV, NPV and diagnostic accuracy increases to $92.31 \%$, $88.24 \%, 92.31 \%, 88.24 \%$ and $90.69 \%$ respectively. 
- $\quad$ So, if scoring system is combined with ultrasonographic finding then correctness of the diagnosis of acute appendicitis increases much more.

\section{Follow Up}

Patients were followed up for a period ranging from 2 to 7 months. No significant complication was detected in any of the patients.

\section{CONCLUSIONS}

When any of the two scoring systems i.e. modified Alvarado score and Ohmann score was used along with US, it increased the sensitivity, specificity, PPV, NPV, diagnostic accuracy and reduced the negative appendectomy rates. So, combination of scoring system with ultrasonography is very helpful to correctly diagnose acute appendicitis in patients presenting with acute right lower quadrant pain of abdomen.

\section{REFERENCES}

[1] Christian FG, Christian P. Diagnostic accuracy of Alvarado score in the diagnosis of aacute appendicitis. Ann R Coll Surg Engl 1992;74:281.

[2] Brunicardi F, Anderson D, Billiar T, et al. Schwartz's Principles of Surgery. 9th edn. McGraw-Hill Professional 2009: p. 1074.

[3] Hardin DM Jr. Acute appendicitis: review and update. Am Fam Physician 1999;60(70):2027-34.

[4] Jones PF. Suspected acute appendicitis: trends in management over 30 years. $\mathrm{Br} \quad \mathrm{J}$ Surg 2001;88(12):1570-7.

[5] Malt RA. The perforated appendix. N Engl J Med 1986;315(24):1546-7.

[6] Douglas CD, Macpherson NE, Davidson PM, et al. Randomised controlled trail of ultrasonography in diagnosis of acute appendicitis incorporating the Alvarado score. BMJ 2000;321(7266):919-22.

[7] Ohmann C, Yang Q. Franke C. Diagnostic scores for acute appendicitis. Abdominal Pain Study group. Eur J Surg 1995;161(4):273-81.

[8] Zielke A, Hasse $\mathrm{C}$, Sitter $\mathrm{H}$, et al. Influence of ultrasound on clinical decision making in acute appendicitis: a prospective study. Eur J Surg 1998;164(3):201-9.
[9] Christian F, Christian GP. A Simple scoring ystem to reduce the negative appendicectomy rate. Ann R Coll Surg Engl 1992;74(4):281-5.

[10] Ohmannn C, Franke C, Yang Q, et al. Diagnostic score for acute appendicitis. Chirurg 1995;66(2):135-41.

[11] Kalan M, Talbot D, Cunliffe WJ, et al. Evaluation of modified Alvarado score in the diagnosis of acute appendicitis, a prospective study. Ann R Coll Surg Engl 1994;76(6):418-9.

[12] Bhattacharjee PK, Chowdhury T, Roy D. Prospective evaluation of modified Alvarado score for diagnosis of acute appendicitis. J Indian Med Assoc 2002;100(5):310-1, 314.

[13] Al-Hashemy AM, Seleem MI. Appraisal of the modified Alvarado score for acute appendicitis in adults. Saudi Med J 2004;25(9):1229-31.

[14] Sooriakumaran P, Lovell D, Brown R. A comparison of clinical judgment vs the modified Alvarado score in acute appendicitis. International Journal of Surgery 2005;3(1):49-52.

[15] Kurane SB, Sangolli MS, Gogate AS. A one year prospective study to compare and evaluate diagnostic accuracy of modified Alvarado score and ultrasonography in acute appendicitis, in adults. Indian J Surg 2008;70(3):125-9.

[16] Abu-Yousef MM, Bleacher JJ, Macer JW, et al. High resolution sonography of acute appendicitis. AJR Am J Roentgenol 1987;149(1):53-8.

[17] Yacoe ME, Jeffrey RB Jr. Sonography of appendicitis and diverticulitis. Radiol Clin North Am 1994;32(5):899-912.

[18] Birnbaum BA, Wilson SR. Appendicitis at the millennium. Radiology 2000;215(2):337-48.

[19] Zielke A, Sitter H, Rampp T, et al. Clinical decision making, ultrasonography and scores for evaluation of suspected acute appendicitis. World J Surg 2001;25(5):578-84.

[20] Debnath J, SreeRam MN, Balani S, et al. Ultrasonography in patients with suspected acute appendicitis. MJAFI 2005;61(3):249-52. 